Please do not remove this page

RMIT

UNIVERSITY

\title{
Experimental investigation of damage progression and strength of countersunk composite joints
}

Chishti, Maajid; Wang, Chun; Thomson, Rodney; Orifici, Adrian

https://researchrepository.rmit.edu.au/esploro/outputs/9921858387901341/filesAndLinks?institution=61RMIT_INST\&index=null

Chishti, M., Wang, C., Thomson, R., \& Orifici, A. (2012). Experimental investigation of damage progression and strength of countersunk composite joints. Composite Structures, 94(3), 865-873.

https://doi.org/10.1016/j.compstruct.2011.10.011

Document Version: Accepted Manuscript

Published Version: https://doi.org/10.1016/j.compstruct.2011.10.011

Repository homepage: https://researchrepository.rmit.edu.au

(c) 2011 Elsevier Ltd. All rights reserved.

Downloaded On 2023/04/26 20:37:07 +1000

Please do not remove this page 
Thank you for downloading this document from the RMIT Research Repository.

The RMIT Research Repository is an open access database showcasing the research outputs of RMIT University researchers.

RMIT Research Repository: http://researchbank.rmit.edu.au/

\section{Citation:}

Chishti, M, Wang, C, Thomson, R and Orifici, A 2012, 'Experimental investigation of damage progression and strength of countersunk composite joints', Composite Structures, vol. 94, no. 3, pp. 865-873.

See this record in the RMIT Research Repository at:

http://researchbank.rmit.edu.au/view/rmit:16987

Version: Accepted Manuscript

Copyright Statement: (c) 2011 Elsevier Ltd. All rights reserved.

Link to Published Version:

http://dx.doi.org/10.1016/j.compstruct.2011.10.011 


\title{
Experimental Investigation of Damage Progression and Strength of Countersunk Composite Joints
}

\author{
Maajid Chishti ${ }^{\text {a }}$, Chun H. Wang ${ }^{\text {a, }}$, Rodney S. Thomson ${ }^{\text {b }}$, Adrian C. Orifici ${ }^{\text {a, }}{ }^{\text {, }}$ \\ ${ }^{a}$ RMIT University, School of Aerospace, Mechanical and Manufacturing Engineering, \\ GPO Box 2476, Melbourne, Victoria 3001, Australia \\ * corresponding author: adrian.orifici@rmit.edu.au, fax +61399256108 \\ ${ }^{\mathrm{b}}$ Cooperative Research Centre for Advanced Composite Structures Ltd, \\ 506 Lorimer Street, Fishermans Bend, Victoria 3207, Australia
}

\begin{abstract}
An experimental investigation is conducted into the damage progression and strength of bolted joints with fibre-reinforced composite laminates and countersunk fasteners. The main goal of the experimental investigation is to characterise the effect of the countersink geometry on the load-carrying capacity of single lap joints in comparison to the straightshank case. The effects of bolt torque, clearance and countersink height ratio on the damage progression and joint strength are also studied. Experimental tests and detailed microscopy studies are conducted on a bearing test specimen with a straight-edged hole, and several single-lap joint configurations with countersunk fasteners. It is found that introduction of the countersunk hole roughly halves the bearing stress, and causes delamination for some configurations. This delamination is primarily located at the start of the countersink region, though is found to be triggered by other damage mechanisms and has only minor influence
\end{abstract}


on the results. Bolt torque increases the density of through-thickness damage though limits its extension from the hole edge, whilst bolt clearance causes localisation of the damage region. Increasing the ratio of the countersink depth to the laminate thickness reduces the extent of bearing and promotes bending, with a change to net section failure at large ratios.

Keywords: Countersunk bolts, single-lap joints, bearing tests, progressive damage

\section{Introduction}

Despite the many advantages of adhesive bonding, bolted joints are still used in aerospace structures because of the ease of assembly/disassembly and airworthiness certification. However, the introduction of bolts leads to complicated three-dimensional (3D) stress fields near the bolt hole [1]. In the case of composite skin structures, the use of countersunk fasteners elevates the stress concentration above that for straight-sided holes. The higher stresses due to the countersunk fastener further reduce the joining efficiency of laminated composites. To take full advantage of fibre-reinforced composite materials in structural elements, it is necessary to investigate techniques to improve the structural efficiencies of bolted joints, particularly those involving countersunk fasteners. This in turn requires a thorough understanding and modelling capabilities of the effect of the countersink geometry and the influence of the joint parameters.

Research in the field of bolted joints has mostly concentrated on straight shank bolts, with limited work on countersunk bolted joints. Various authors [2, 3] have found the primary failure mode in pin-bearing damage is shear cracking formed by accumulated compression failure in each individual ply of the laminate. Detailed microscopy has found 
that the principal damage mechanisms of the shear cracks are fibre kinking, fibre-matrix shearing and matrix compression. Delamination has also been found to be a major failure mode in bearing damage [4], particularly in interaction with other modes.

Research on the influence of bolted joint parameters on the joint strength and damage progression has also been dominated by investigations into straight-shank bolts. Bolt torque (BT) has been investigated by several authors for straight-shank bolts $[5,6]$ and found to increase bearing and failure loads, as well as limit delamination. Clearance (CL) in straightshank bolt holes has been found to reduce the bolt contact area [7-9], affecting the load transfer, high stress regions and joint bearing loads. With regards to countersunk joints, recommendations for joint design to promote bearing failure are given in an ASTM standard [10], and summarised in Figure 1, though the effects of variation within these guidelines are not covered.

In contrast to the considerable literature available on straight-shank bolts, the literature with regards to countersunk joints is not as comprehensive. A few investigations have focused on the contact condition of the bolt $[8,11,12]$, or the application with multibolt joints [13]. These investigations have typically focused on describing the joint behaviour using the load history, and detailed microscopy of countersunk joints under a range of joint configurations have not been published in open literature. Further, the majority of literature on composite bolted joints relates to uni-directional tape material, and the damage mechanisms and joint behaviour of laminates manufactured using fabric plies have not been reported. 
In this paper, results are presented from an experimental investigation into the damage progression and strength of countersunk composite single-lap joints. The specimens investigated are manufactured from fabric material with variations in bolt torque, clearance and countersink height to laminate thickness (HT) ratio $h / t$. A focus of the investigation is a detailed study of the load-carrying capability and damage mode initiation, progression and interaction. Results from a numerical investigation into the stress distributions are also presented, to provide further insight into the load paths and stress distributions for each configuration.

\section{Specimen Configuration}

Experimental tests were conducted in two configurations: a bearing test, and singlelap joints with countersunk bolts. Both specimens were designed according to the recommendations to promote bearing failure in the ASTM standard [10]. The details of the specimens are given in Figure 2 and Table 1, where the bearing test was equivalent to the lower laminate of the single-lap joint (with no extensometer tab). The bearing test used a straight-edge hole, whilst all other specimens were single-lap joints with countersunk holes. The specimens were all manufactured using plain weave carbon/epoxy T300/970 pre-preg (nominal ply thickness $0.22 \mathrm{~mm}$ ). Specimens were tested in a $100 \mathrm{kN}$ MTS hydraulic test machine. Strain gauges (SGs) were used as shown in Figure 2, though the bearing test used only one strain gauge at the SG4 location.

In the bearing test, a single laminate with a straight-edge circular hole was gripped on one end and loaded in bearing by a steel pin through the hole. An extensometer was placed between the laminate edge and the loading grip. In the single-lap joints test, the specimens 
were gripped on the edge of each laminate and loaded in tension. An extensometer was placed between tabs as shown in Figure 2. Variations in the single-lap joints included different levels of bolt torque, bolt clearance, and countersink height to laminate thickness ratio $h / t$, each at three levels as summarised in Table 2. Bolt torque was introduced using a calibrated torque wrench, and clearance was introduced by increasing the diameter of the straight-edge portion of the bolt hole only. The specimens were loaded in displacement control at $0.5 \mathrm{~mm} / \mathrm{min}$ until ultimate failure, though one bearing test specimen was only loaded until the onset of non-linearity.

Following testing, microscopy was conducted on one specimen of each configuration, and for the bearing test the specimen loaded to only the onset of non-linearity was also inspected. Sections were taken along the loading direction ( $x$-axis) and at $45^{\circ}$ to the loading direction, where the cross-section labelling for microscopy and damage analysis is shown in Figure 3. Each laminate was inspected at the hole edge on the opposite side of the bolt to where the laminate was gripped, as this was the location of bolt contact and bearing damage. The microscopy images were all taken at $5 \times$ magnification using a Leica optical microscope.

For each test, the bearing load was calculated according to recommendations in the ASTM standard [10], which involves determining the load associated with bearing displacement that is $4 \%$ of the bolt diameter. As the displacement was measured from tabs on either side of the bolt, instead of directly on the bolt as dictated by the standard [10], the displacement results are only indicative of bearing displacement. The applied stress was determined by dividing the applied load by the bearing area $(D \times t)$. In this paper, applied 
stress versus extensometer displacement (stress-displacement) results are shown for one specimen of each configuration, as representative of the average of the three repetitions.

\section{Numerical Analysis}

Numerical analysis was conducted to study the stress distribution throughout the joints, as a means of providing further insight into the experimentally observed damage mechanisms. The analysis was conducted using Abaqus 6.9 [14], for both the bearing test and single-lap joints. The models used 3D continuum shells for the laminates and rigid elements for the bolt and nut, with friction-based contact implemented on all contactable surfaces. Bolt torque was introduced by applying an equivalent displacement of the bolt into the nut in a pre-loading analysis step, before the bolt-nut assembly was rigidly connected for the tensile loading. The in-plane and through-thickness mesh densities were determined using mesh sensitivity investigations, which are not included here for brevity. The in-plane mesh distribution is shown in Figure 4(a). In the through-thickness direction, the bearing test model used 32 elements, and the single-lap joint models (shown in Figure 4(b)) used 4 elements for the lower laminate and between 2 and 4 elements for the upper laminate depending on the hole geometry. Further detail on the model is provided in a previous publication [15], and the use of the model for detailed progressive failure analysis will be the subject of future publications.

In analysing the results, stresses in the radius $(r)$ direction were considered, as shown in the cylindrical coordinate system in Figure 3. All models were taken to an applied load of $1.5 \mathrm{kN}$, and stresses were normalised using the maximum stress in the bearing test. This normalised radial stress is plotted as a function of the angular coordinate $\theta$ for a given ply 
location. There were two $0^{\circ}$ ply locations studied, as shown in Figure 3, which corresponded to the start of the countersink region and the shear plane.

\section{Results}

\subsection{Bearing tests}

The results for the bearing test specimens are shown in Table 3, Figure 5 and Figure 6. The stress-displacement results in Figure 5 show a linear region and a drop in stress at the onset of non-linearity. The non-linear region is characterised by gradually increasing stress with increasing applied displacement, up to a maximum stress, which is higher than the stress for non-linearity onset.

The results of the micrographs in Figure 6 show that the onset of non-linearity is associated with significant bearing damage. This damage is characterised by interlaminar and intralaminar shear cracks comprising of fibre kinking, matrix shear and matrix compression failure. Delamination was present at the onset non-linearity, but is not considered a major damage mode, and is not visible at ultimate stress due to the considerable edge loss and fraying of the section. Inspection of the $45^{\circ}$ sections showed similar damage mechanisms but considerably less damage, as the extent of damage reduced around the circumference of the hole.

\subsection{Countersunk joints: Effect of countersunk hole}

The experimental and numerical results are summarised respectively in Table 3 and Table 4, numerical results comparing the bearing test with a single-lap joint are shown in Figure 7, and the results investigating the effect of bolt torque are shown in Figure 8 to 
Figure 10. These results are used in this section to discuss the overall effect of introducing the countersunk hole geometry, and are discussed in subsequent sections with regards to the specific effects of the joint parameters.

The results in Table 3 show that the introduction of the countersunk hole caused the bearing stress to be reduced to at least half of the bearing test value, whilst the ultimate stress increased by a small amount. This is also seen in Figure 8 from the stressdisplacement history for the countersunk hole with no bolt torque (BT_0), which is characterised by a short linear region and extended non-linear region in comparison with the bearing test results in Figure 5. However, the exact effect of the countersunk hole is difficult to quantify from the results as different specimen configurations were used, and the single-lap joints also involve some degree of bending.

The numerical results in Figure 7 and Table 4 compare the radial stress distribution of the bearing test with the countersunk joint with no bolt torque. From these results, the introduction of the countersunk geometry increased the radial stress at the shear plane and start of the countersink region by $43 \%$ and a $67 \%$ respectively, relative to the maximum stress in the bearing test. This agrees with the results from other researchers $[11,16]$, where the introduction of a countersunk hole has been found to increase the stress concentration factor, particularly at the start of the countersunk region.

The micrographs in Figure 9 and Figure 10 show $0^{\circ}$ sections of the upper and lower laminate at BT_2.1. These show that the introduction of the countersunk hole led to an angular damage region in the upper laminate (Figure 9), as the bearing damage remained 
parallel to the hole edge. Similar damage mechanisms to the bearing test were seen, and include intralaminar and interlaminar shear cracks within the bearing damage region and secondary delaminations outside of the bearing damage region and close to the free surfaces. Additionally, delamination was also evident at the start of the countersink within the bearing damage region (Figure 9), and is termed primary delamination as it is not a secondary effect of the shear cracks. The damage mechanisms in the lower laminate (Figure 10) were similar to the bearing test, though bolt rotation led to an angular damage region at the bottom of the laminate that was not seen for the bearing test. The $45^{\circ}$ sections indicated that damage reduced around the hole circumference, where in particular the primary delamination was not seen at the $45^{\circ}$ locations.

\subsection{Countersunk joints: Effect of bolt torque}

The results of the single-lap joints investigating the effect of bolt torque are shown in Table 3, Table 4 and Figure 8 to Figure 10. The results in Table 3 show that the application of $2.1 \mathrm{~N}$ m of bolt torque (BT_2.1) from the finger-tight case (BT_0) led to a significant increase in bearing stress (33\%), whilst only a minor increase (3\%) in the ultimate failure stress. Doubling the amount of bolt torque did not show any further improvement, with only marginal changes in bearing stress and ultimate stress. This is also evident from the stress-displacement history in Figure 8, where increasing bolt torque increased the length of the linear region. The insensitivity of ultimate failure load to bolt torque has also been reported by other authors [17-19], over similar bolt torque ranges. 
The micrographs in Figure 9 and Figure 10 show $0^{\circ}$ sections of the upper and lower laminate at BT_2.1. From these, and the micrographs not shown at $45^{\circ}$ and at other BT levels, a detailed study of the effect of bolt torque on through-thickness damage profile was conducted. The introduction of bolt torque reduced the length of the bearing damage region away from the hole, but increased the density of shear cracks through the thickness. Bolt torque also prevented fraying of the laminate as seen in the bearing test (Figure 6(b)) and BT_0. Instead, bulging was promoted at the outer surfaces of the laminate as shown in Figure 9 and Figure 10. Despite this, primary delamination was seen at all levels of bolt torque at the same location.

The numerical results in Table 4 compare the radial stress for the countersunk joints with varying bolt torque. From these results, the application of moderate bolt torque caused a small increase in radial stress at the countersink location, whilst high torque was seen to reduce the radial stresses in both locations. These results agree in part with the experimental results in terms of increasing bolt torque leading to an improvement in joint performance, the occurrence of delamination at the start of the countersink region, and the reduction in the extent of bearing damage.

\subsection{Countersunk joints: Effect of bolt clearance}

The results of the single-lap joints investigating the effect of bolt clearance are shown in Table 3 and Figure 11 to Figure 13. The results in Table 3 show that the introduction of $220 \mu \mathrm{m}$ of clearance led to a significant (17\%) reduction in the bearing stress, though only a slight reduction in the ultimate stress. Doubling the clearance only reduced the bearing 
stress by $7 \%$, with a further slight reduction in ultimate stress. From the stress-displacement history in Figure 11, the introduction of clearance caused a shift towards larger displacements and introduced multiple stages in the linear region. Both of these effects are attributed to the sequence of loading of the joint with clearance, as shown in Figure 12, where the bolt first contacts one laminate, then rotates to contact the other laminate. The small reduction in ultimate stress as a result of introducing clearance agrees with results from other authors investigating countersunk joints $[8,9]$, though is in contrast to the large influence of clearance reported by other researchers studying straight-edge holes [7, 20].

The micrographs in Figure 13 and those not shown at $45^{\circ}$ and other CL levels were used to study the through-thickness damage profile. For these images, the locations correspond to those indicated in Figure 3, and match those shown in Figure 9 and Figure 10, where the labelling in these latter two figures applies equally though has been omitted for clarity. The introduction of clearance increased the damage close to the shear plane, or interface between the upper and lower laminates. This is seen at the bottom of the upper laminate in Figure 13(a), and the top of the lower laminate in Figure 13(b), in comparison with the neat fit hole damage shown in Figure 9 and Figure 10. This changed the straightedge damage regions to angular damage regions, so that both laminates contained two intersecting angular damage regions. This damage pattern also suppressed the occurrence of primary delamination, which was not seen in any joint with clearance. The increase in damage is explained schematically in Figure 12 by the sequence of loading in a clearance joint leading to high stress regions at the shear plane. These locations also had a higher 
density of through-thickness cracks, though the length of damage away from the hole was reduced with increasing clearance.

Furthermore, the normalised radial stress results in Table 4 demonstrate the significant increase in stresses at the shear plane with the introduction of clearance. From these results, the introduction of clearance is seen to increase the stress in the central section by almost four times. However, further increasing the clearance does not continue to increase the radial stresses. Stresses at the start of the countersink region also drop dramatically with the introduction of clearance, further highlighting the localisation of stresses at the shear plane. These results demonstrate the mechanism for the increased damage at the shear plane, and also explain the large difference in joint behaviour between the no clearance and moderate clearance cases.

\subsection{Countersunk joints: Effect of height ratio}

The results of the single-lap joints investigating the effect of height ratio are shown in Table 3, Figure 14 and Figure 15. The largest height ratio (HT_0.76) specimens failed in bending, with behaviour distinctly different from all other countersink joint configurations. This is illustrated in the stress-displacement history in Figure 14, and the net tension failure mode associated with bending shown in Figure 15(b). From Table 3, the bearing stress for the HT_0.76 specimen also shows a large coefficient of variation (33\%), indicating the difficulties in applying this measure of bearing performance to joints failing in bending. Very limited work is available in literature on the effects of countersunk height ratio for single lap composite bolted joints, though similarly large reductions in ultimate strength at high height ratios have been reported [21]. 
For the specimens that failed in bearing, increasing the height ratio had a negligible effect on the bearing stress, and only a minor (5\%) reduction in ultimate stress. The stressdisplacement data shown in Figure 14 also illustrates the close comparison for theses two levels of height ratio. Increasing the height ratio increased the bending displacement, or displacement in the through-thickness direction. This is associated with a smaller straightedge region, which produces larger load eccentricity as it carries the majority of the load. Inspection of the micrographs at $0^{\circ}$ and $45^{\circ}$ at the two bearing failure HT levels also showed similar levels of damage. The micrographs did show that increasing the height ratio increased the extent of through-thickness damage close to the shear plane in both laminates, with the upper laminate showing an angular damage at the straight edge. Furthermore, no primary delamination occurred at increased height ratios, including HT_0.76 where bending failure was seen.

The micrograph findings are reinforced by the radial stress results shown in Table 4 for the specimens that failed in bearing. In these results, increasing the countersink height ratio increases the radial stress by almost four times whilst halving the stress at the start of the countersink, which explains the increased density of shear cracks seen at the shear plane. The radial stress results do not explain the relative insensitivity of the bearing and ultimate stress to the height ratio, which is likely due to these parameters being more closely related to the use of the same laminate, instead of the change in hole geometry.

\section{Discussion}

The results of this investigation are informative when viewed in the context of various recommendations relating to joint design. The maximum shear-off torque for the 
bolt-nut assembly is from $4.5 \mathrm{~N} \mathrm{~m}$ to $5.6 \mathrm{~N} \mathrm{~m}$ [22], so that the bolt torque levels investigated represent approximately $0 \%, 41 \%$ and $83 \%$ of this value. The results in this work showed that whilst no torque involves lower load-carrying capacity, only mild levels of torque are required for higher bearing stresses. However, the reduced length of bearing damage and increased density of through-thickness cracks, in particular those under the countersunk bolt head, are problematic from an inspection point of view.

With regards to clearance, current aerospace guidelines recommend a maximum of $1 \%$ of the bolt hole diameter [9]. The configurations in this investigation represent $5 \%$ and $9 \%$ of the bolt hole diameter. A $17 \%$ reduction in bearing stress at a clearance of $5 \%$ hole diameter (CL_240) was seen, which highlights the importance of avoiding clearance for design purposes. Despite this, the effect on the ultimate strength was minimal. This may be due to the beneficial effects of bolt torque, where other researchers investigating clearance with pin connections have reported significant influence of clearance [7, 20]. Although negligible difference was seen in the overall load-carrying capacity, the addition of clearance both localised and increased the density of damage, which can be important for damage tolerance considerations.

For height ratio, Ref. [10] recommends a range from 0.0 (no countersink) to 0.7 to promote bearing failure. The configurations in this work cover the upper end of this range where the effects of bending are more prominent, with the highest ratio of 0.76 falling outside the recommended range. As such, the highest ratio configuration showed the largest amount of bending, and failed in net section failure due to excessive bending stresses. For the configurations that failed in bearing, the difference in bearing stress and ultimate stress 
were negligible, confirming the performance of countersunk joints within this recommended range.

The investigation in this work was focused on studying the effect of joint parameters, so that the experimental program covered specimens focusing on changing each of these parameters one at a time. As such, the complete database of test results does not provide enough experimental evidence to assess whether there is any interaction between the various joint parameters. For example, the results for changing clearance were studied at one bolt torque ratio, and whilst obviously being influenced by this level of bolt torque, any interaction with the degree of bolt torque is unable to be assessed. A more broad experimental program would be required to assess whether the results from varying multiple joint parameters differ from results seen when the parameters are individually varied.

With regards to the use of fabric material, the results do not indicate any specific damage mechanism or behavioural aspect that is unique, or has not been generally reported in other publications for UD ply laminates. Comparing the damage mechanisms of delamination and matrix shear cracking between these results and others mentioned throughout this paper, there is nothing to suggest that the fibre architecture of the fabric plies makes a significant contribution to bearing damage. Whilst it is well known that the fabric architecture leads to reduced in-plane stiffness, amongst other effects, the results in this paper suggest that the initiation and progression of bearing damage is similar between fabric and UD plies. 
The experimental results in this work provide valuable insight and detailed information on the damage mechanisms and load-carrying capability of composite countersunk joints. This information is critical for developing a validated numerical modelling approach. Such a validated methodology can provide further insight and more detailed information on the damage and strength characteristics of countersunk joints. This is the subject of ongoing research.

\section{Conclusion}

An experimental investigation has been conducted into the damage progression and strength of bolted joints with countersunk and straight-edge fasteners. The following conclusions can be drawn from the experimental tests and detailed microscopy studies:

- Introduction of the countersunk hole causes an offset of the local bearing damage region such that it remains parallel to the hole edge. The bearing stress is roughly halved with only slight increase in ultimate stress.

- The introduction of the countersunk hole can also cause delamination. This is primarily located at the start of the countersink region, though has only minor influence on the joint behaviour.

- Bolt torque increases the density of through-thickness damage whilst limiting its extension from the hole edge, and only mild bolt torque is required to increase the bearing stress. 
- Bolt clearance causes the damage region to become more localised and reduces the bearing stress, though has minimal effect on the ultimate stress.

- Increasing the $h / t$ ratio reduces the extent of bearing damage and promotes bending. This has only a small effect on the joint load-carrying capacity, except at high ratios where the failure mode changes to net section failure.

\section{Acknowledgements}

The authors acknowledge the financial support provided by the Australian

Postgraduate Award. The technical support of Mr Peter Tkatchyk (RMIT University) and Mr Daniel Bitton (CRC-ACS) is also kindly acknowledged. 


\section{References}

[1] Tserpes KI, Papanikos P, Kermanidis T. A three-dimensional progressive damage model for bolted joints in composite laminates subjected to tensile loading. Fatigue \& Fracture of Engineering Materials and Structures. 2001;24:663-75.

[2] Wang HS, Hung CL, Chang FK. Bearing failure of bolted composite joints. Part I: Experimental characterisation. Journal of Composite Materials. 1996;30:1284-313.

[3] Camanho PP, Bowron S, Matthews FL. Failure mechanisms in bolted CFRP. Journal of Reinforced Plastics and Composites. 1998;17:205-33.

[4] Ireman T, Ranvik T, Erikkson I. On damage development in mechanically fastened composite laminates. Composite Structures. 2000;49:151-71.

[5] Camanho PP, Matthews FL. Stress analysis and strength prediction of mechanically fastened joints in FRP: a review. Composites Part A: Applied Science and Manufacturing. $1997 ; 28: 529-47$

[6] Thoppul SD, Finegan J, Gibson RF. Mechanics of mechanically fastened joints in polymer-matrix composite structures - A review. Composites Science and Technology. 2008;69:301-29.

[7] Hyer MW, Klang EC, Cooper DE. The effects of pin elasticity, clearance and friction on the stresses in a pin-loaded orthotropic plate. Journal of Composite Materials. 1987;21:190-206. 
[8] Kelly G, Hallström S. Bearing strength of carbon fibre/epoxy laminates: effects of bolthole clearance. Composites Part B: Engineering. 2004;35:331-43.

[9] McCarthy CT, McCarthy MA, Lawlor VP. Progressive damage analysis of multi-bolt composite joints with variable bolt-hole clearances. Composites Part B: Engineering. 2005;36:290-305.

[10] ASTM D5961, Standard test method for bearing response of polymer matrix composite laminates. American Society for Testing and Materials; 2007.

[11] Ireman T. Three-dimensional stress analysis of bolted single-lap composite joints. Composite Structures. 1998;43:195-216.

[12] McCarthy MA, Lawlor VP, Stanley WF, McCarthy CT. Bolt-hole clearance effects and strength criteria in single-bolt, single-lap, composite bolted joints. Composite Science and Technology. 2002;62:1415-31.

[13] Starikov R, Schön J. Quasi-static behaviour of composite joints with countersunk composite and metal fasteners. Composites Part B: Engineering. 2001;32:401-11.

[14] Abaqus ${ }^{\circledR}$ 6.9 Documentation. Providence, RI, USA: Dassault Systèmes Simulia Corporation; 2010.

[15] Chishti M, Wang CH, Thomson RS, Orifici AC. Progressive damage in single lap countersunk composite joints. 9th World Congress on Computational Mechanics and 4th Asian Pacific Congress on Computational Mechanics. Sydney, Australia, 19-23 July, 2010. 
[16] Bhargava A, Shivakumar KN. Three-dimensional tensile stress concentration in countersunk rivet holes. The Aeronautical Journal. 2007;111:777-86.

[17] Khashaba UA, Sallam HEM, Al-Shorbagy AE, Seif MA. Effect of washer size and tightening torque on the performance of bolted joints in composite structures. Composite Structures. 2005;73:310-7.

[18] Cooper C, Turvey J. Effects of joint geometry and bolt torque on the structural performance of single bolt tension joints in pultruded GRP sheet material. Composite Structures. 1995;32:217-26.

[19] Sun HT, Chang FK, Qing X. The response of composite joints with bolt clamping loads, Part II Model verification. Journal of Composite Materials. 2002;36:69-92.

[20] Naik RA, Crews JH. Stress analysis method for a clearance-fit bolt under bearing condition. AIAA Journal. 1985;24:1348-53.

[21] Garrett RA. Effect of manufacturing defects and service-induced damage on the strength of aircraft composite structures. Composite Materials: Testing and Design (Seventh Conference), ASTM STP 775: American Society for Testing and Materials, PA, USA; 1986.

[22] Hi-Lok ${ }^{\circledR}$ Standards. Hi-Shear Corporation, Torrance, CA, USA; 2001. 


\section{Figure Captions}

Figure 1: Specimen design guidelines to promote bearing failure (adapted from Ref. [10])

Figure 2: Countersunk joint geometry and dimensions ( $\mathrm{mm})$, strain gauge locations and extensometer tabs

Figure 3: Cross-section labelling

Figure 4: Numerical model. (a) In-plane mesh. (b) Single-lap joint.

Figure 5: Bearing test, stress-displacement (test \#2)

Figure 6: Bearing test $0^{\circ}$ sections (a) Undamaged (b) Non-linearity onset (c) Ultimate stress

Figure 7: Normalised radial stress for the bearing test and countersunk joint with no bolt torque

Figure 8: Countersunk joints, stress-displacement, bolt torque investigation

Figure 9: Countersunk joint $0^{\circ}$ section, BT_2.1 upper laminate

Figure 10: Countersunk joint $0^{\circ}$ section, BT_2.1 lower laminate

Figure 11: Countersunk joints, stress-displacement, bolt clearance investigation

Figure 12: Countersunk joint, load sequence with clearance

Figure 13: Countersunk joint $0^{\circ}$ section, $\mathrm{CL} \_2$

Figure 14: Countersunk joints, stress-displacement, height ratio investigation

Figure 15: Countersunk joint upper laminate (countersink side) following ultimate failure 
Table 1: Specimen dimensions (mm)

\begin{tabular}{|l|l|l|l|l|}
\hline & $t$ & Fabric ply layup & $D$ & $A$ \\
\hline Bearing & 3.52 & {$[0,45]_{4 \mathrm{~S}}$} & 6.35 & $\mathrm{n} / \mathrm{a}$ \\
\hline BT (all) & 3.52 & {$[0,45]_{4 \mathrm{~S}}$} & 4.76 & 9.56 \\
\hline CL (all) & 3.52 & {$[0,45]_{4 \mathrm{~S}}$} & 4.76 & 9.56 \\
\hline HT_0.56 & 3.52 & {$[0,45]_{4 \mathrm{~S}}$} & 4.76 & 9.56 \\
\hline HT_0.64 & 3.08 & {$\left[(0,45)_{3}, 0\right]_{\mathrm{S}}$} & 4.76 & 9.56 \\
\hline HT_0.76 & 3.52 & {$[0,45]_{4 \mathrm{~S}}$} & 6.35 & 12.71 \\
\hline
\end{tabular}

Table 2: Specimen details

\begin{tabular}{|l|l|l|l|l|}
\hline & Bolt torque $(\mathrm{N} \mathrm{m})$ & Clearance $(\mu \mathrm{m})$ & $h / t$ & Number of specimens* \\
\hline Bearing & $\mathrm{n} / \mathrm{a}$ & $\mathrm{n} / \mathrm{a}$ & $\mathrm{n} / \mathrm{a}$ & 4 \\
\hline BT_0 & 0 (finger tight) & 0 & 0.56 & 3 \\
\hline BT_2.1 & 2.103 & 0 & 0.56 & 3 \\
\hline BT_4.2 & 4.206 & 0 & 0.56 & 3 \\
\hline CL_0 & 2.103 & 0 & 0.56 & 3 \\
\hline CL_240 & 2.103 & 240 & 0.56 & 3 \\
\hline CL_440 & 2.103 & 440 & 0.56 & 3 \\
\hline HT_0.56 & 2.103 & 0 & 0.56 & 3 \\
\hline HT_0.64 & 2.103 & 0 & 0.64 & 3 \\
\hline HT_0.76 & 2.103 & 0 & 0.76 & 3 \\
\hline
\end{tabular}

* BT_2.1, CL_0 and HT_0.56 all represent the same configuration and the same specimens 
Table 3: Experimental results, average stress (coefficient of variation in parentheses)

\begin{tabular}{|l|l|l|l|l|}
\hline & Bearing Stress (MPa) & & Ultimate Stress (MPa) & \\
\hline Bearing & $409(5 \%)$ & & $571(3 \%)$ & \\
\hline BT_0 & $142(4 \%)$ & $624(0.5 \%)$ & \\
\hline BT_2.1 & $190(10 \%)$ & $646(3 \%)$ & \\
\hline BT_4.2 & $184(5 \%)$ & $669(0.5 \%)$ & \\
\hline CL_0 & $190(10 \%)$ & $646(3 \%)$ & \\
\hline CL_240 & $158(4 \%)$ & $636(2 \%)$ & \\
\hline CL_440 & $147(11 \%)$ & $615(2 \%)$ & \\
\hline HT_0.56 & $190(10 \%)$ & & $646(3 \%)$ & \\
\hline HT_0.64 & $192(10 \%)$ & & $565 *(4 \%)$ & \\
\hline HT_0.76 & $107(33 \%)$ & & & \\
\hline
\end{tabular}

* Net tension failure mode (all other configurations failed in bearing) 
Table 4: Numerical results, radial stress concentration factor, $0^{\circ}$ ply at hole location $\theta=0$

\begin{tabular}{|l|l|l|l|l|}
\hline & Shear plane & & Start of countersink & \\
\hline Bearing & 1.0 & & - & \\
\hline BT_0 & 1.43 & & 1.67 & \\
\hline BT_2.1 & 1.39 & & 1.83 & \\
\hline BT_4.2 & -0.17 & & 0.94 & \\
\hline CL_0 & 1.39 & & 1.83 & \\
\hline CL_240 & 3.95 & & -0.27 & \\
\hline CL_440 & 3.84 & & -0.27 & \\
\hline HT_0.56 & 1.39 & & 1.83 & \\
\hline HT_0.64 & 4.16 & & 0.90 & \\
\hline HT_0.76 & 2.27 & & -0.37 & \\
\hline
\end{tabular}




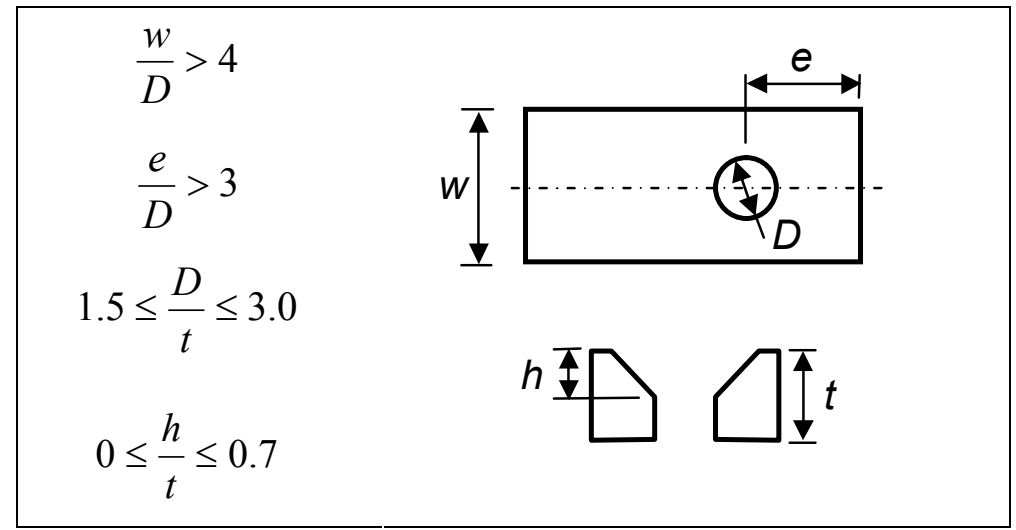

Figure 1: Specimen design guidelines to promote bearing failure (adapted from Ref. [10])
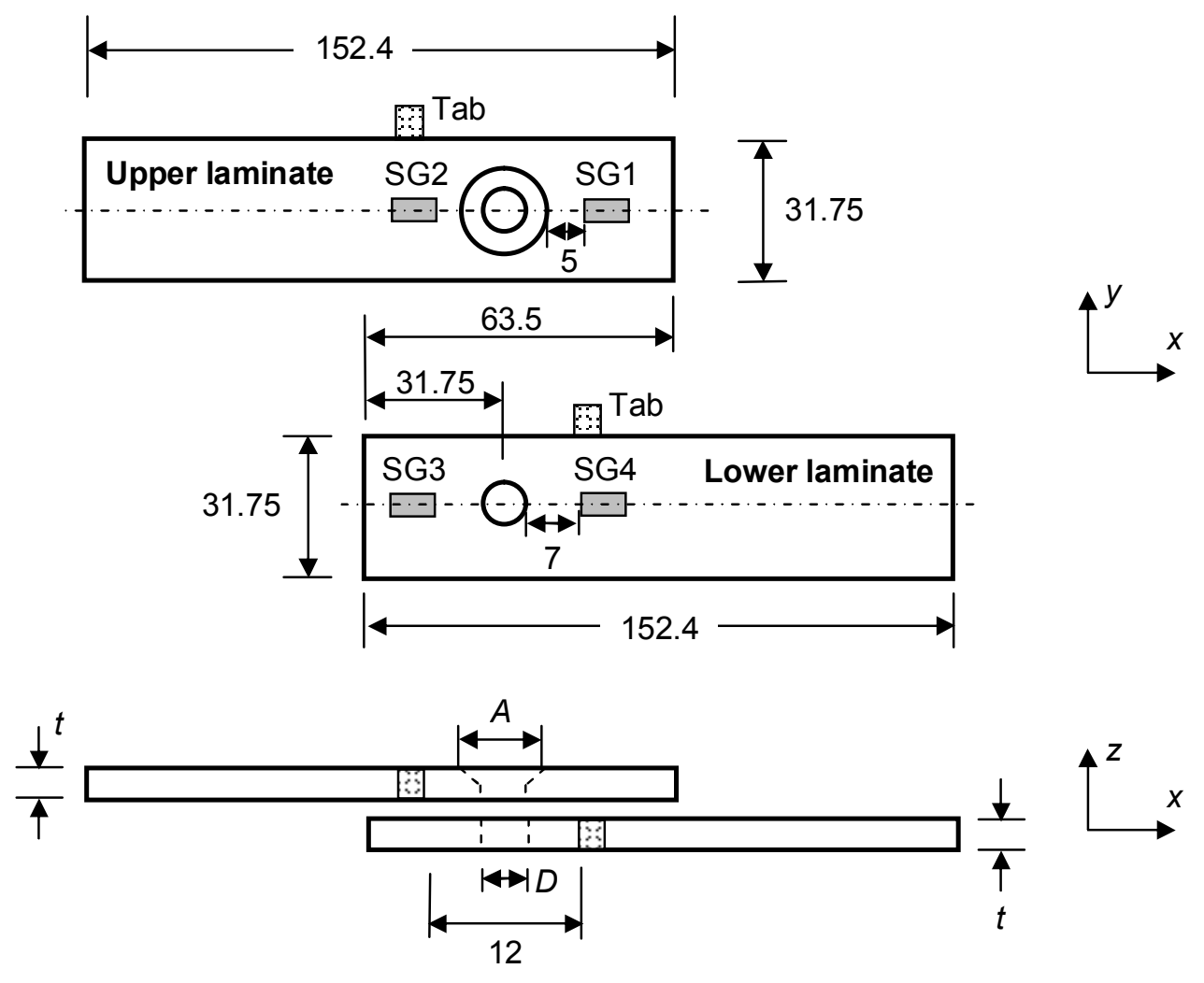

Figure 2: Countersunk joint geometry and dimensions (mm), strain gauge locations and extensometer tabs 

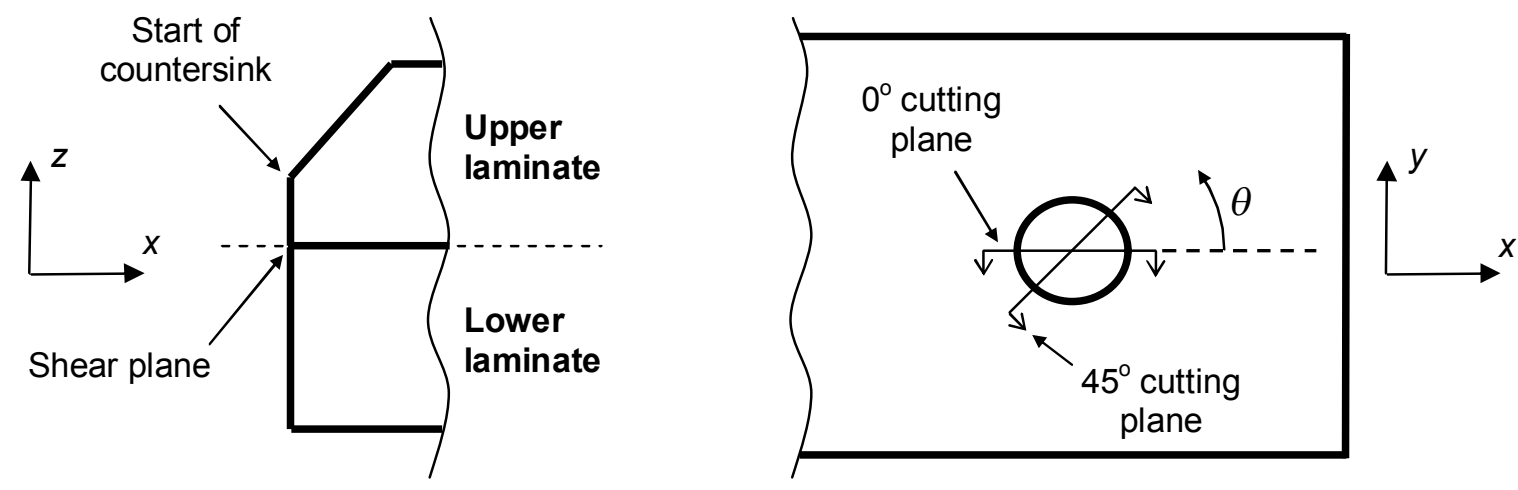

Figure 3: Cross-section labelling

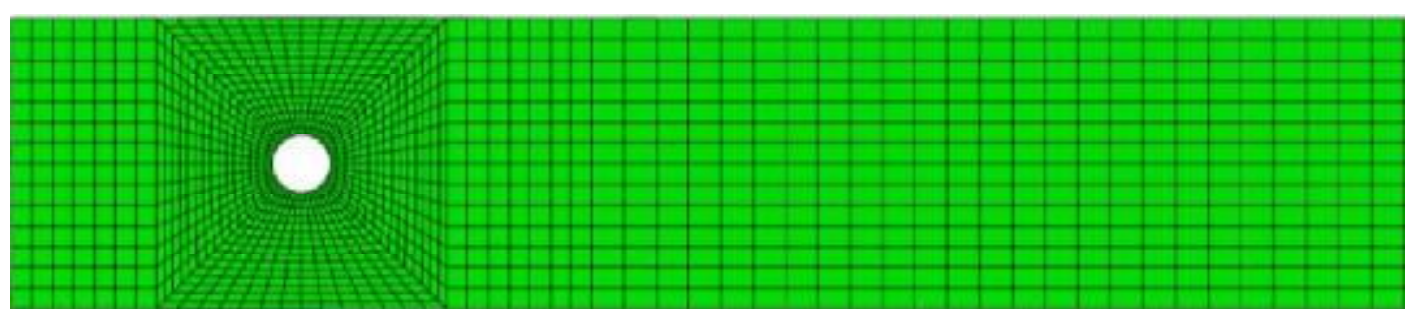

(a)

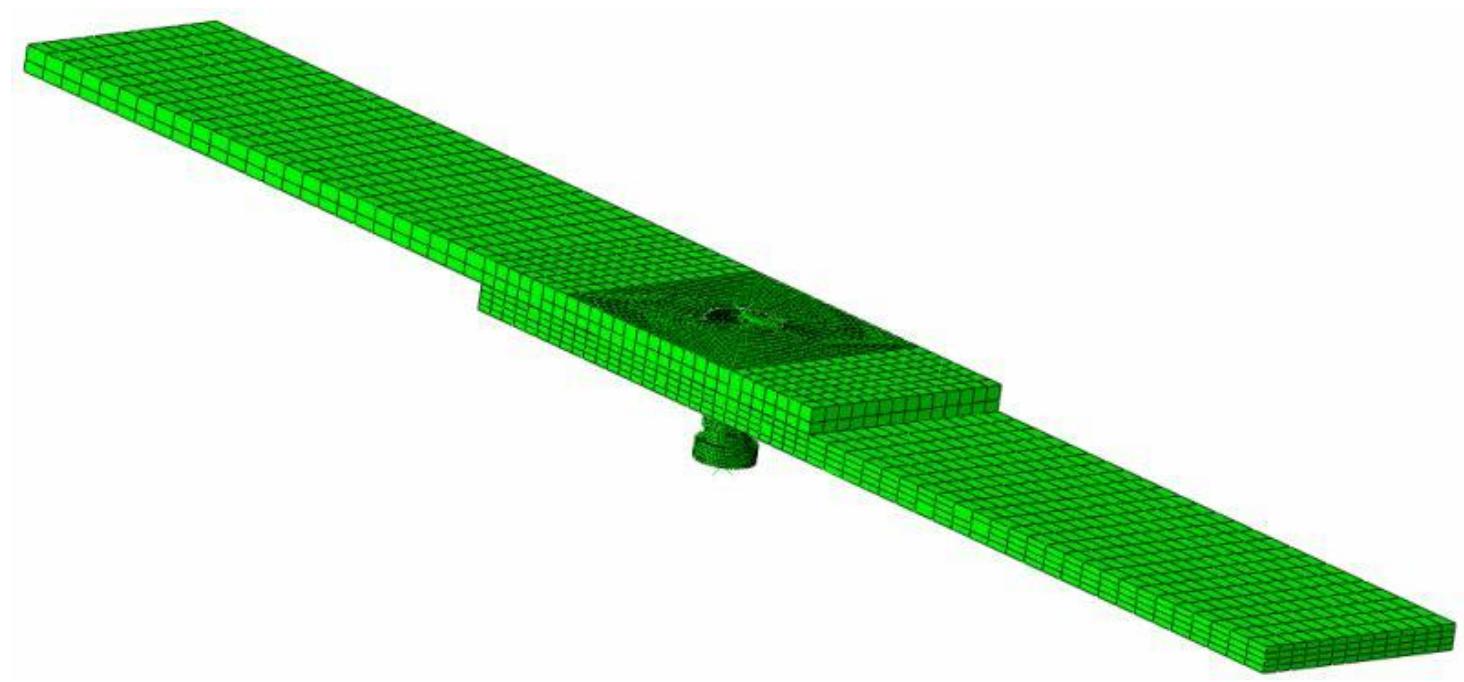

(b)

Figure 4: Numerical model. (a) In-plane mesh. (b) Single-lap joint. 


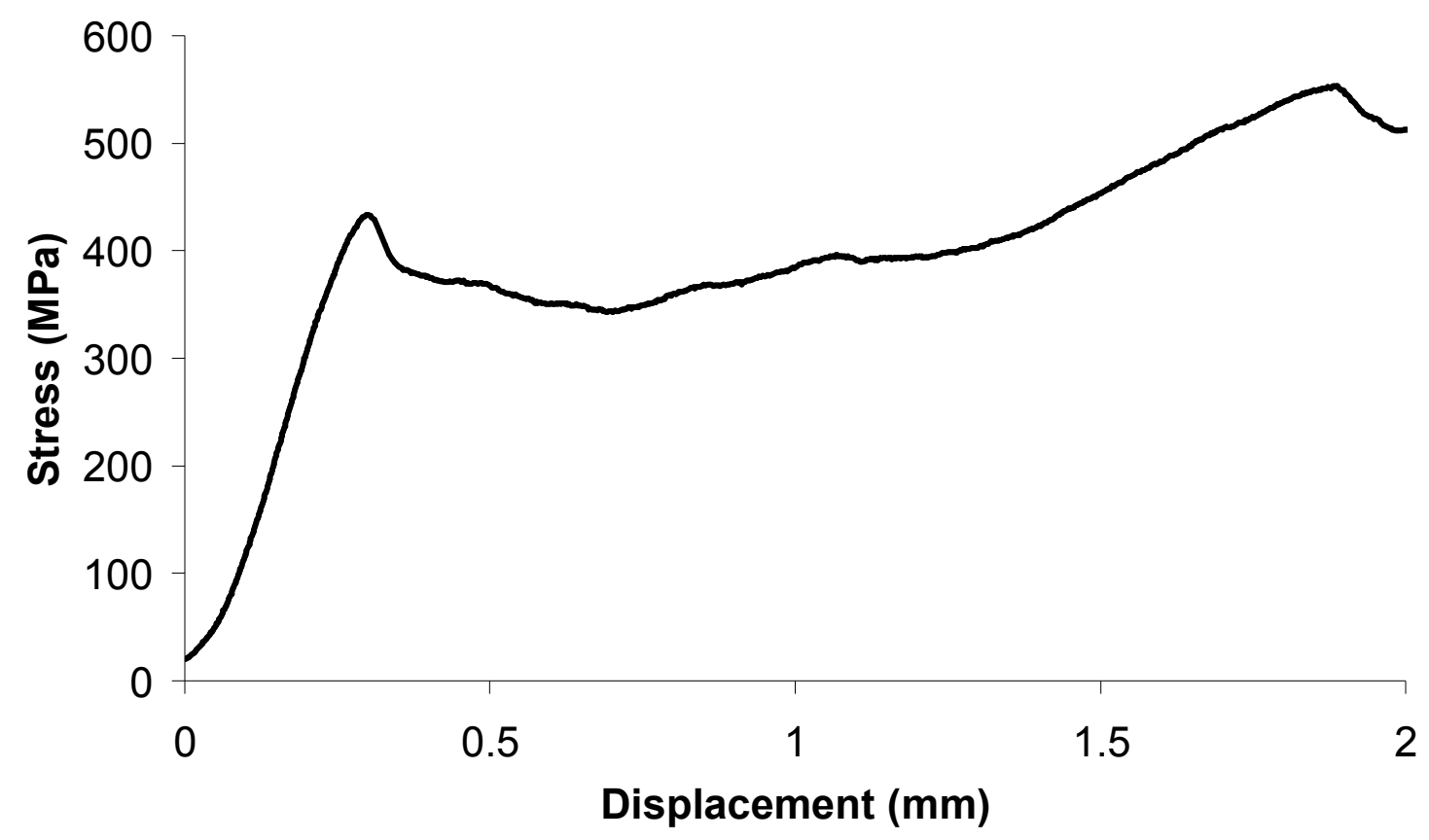

Figure 5: Bearing test, stress-displacement (test \#2)

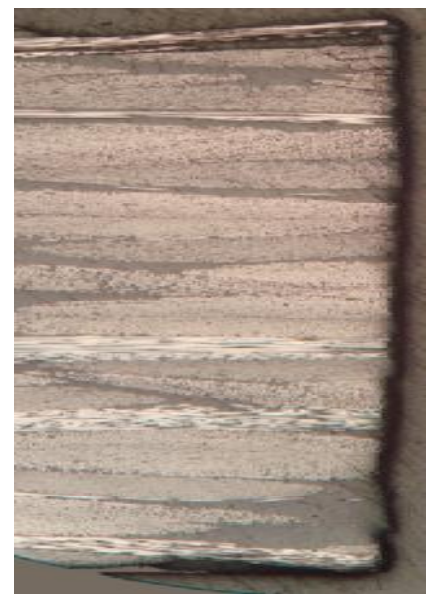

(a)

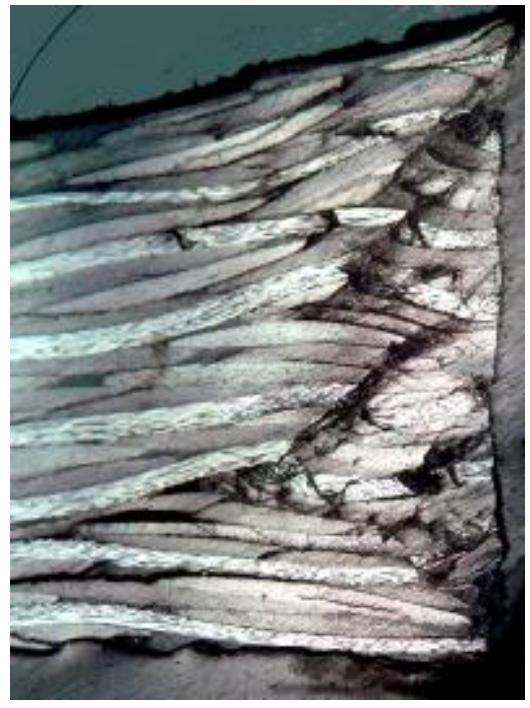

(b)

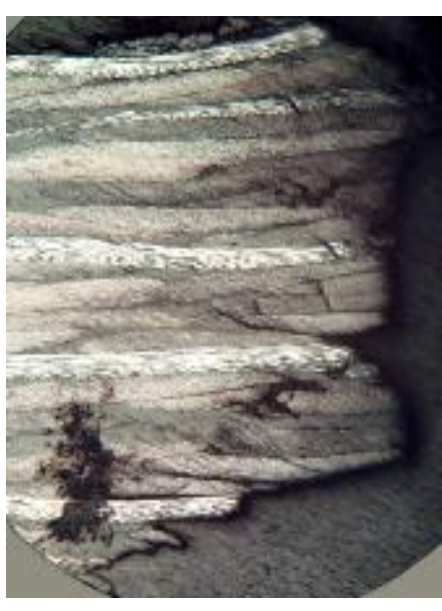

(c)

Figure 6: Bearing test $0^{\circ}$ sections (a) Undamaged (b) Non-linearity onset (c) Ultimate stress 


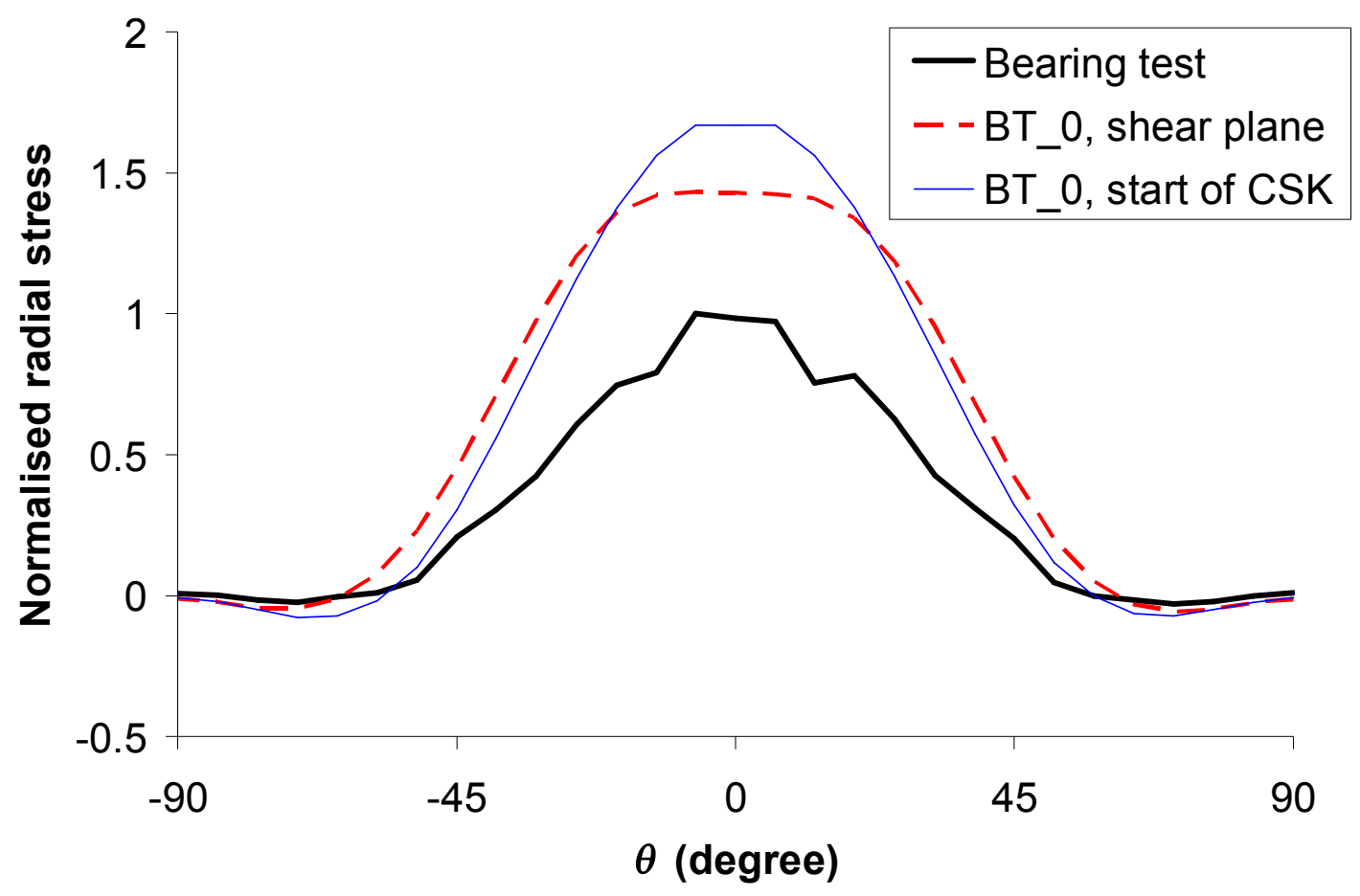

Figure 7: Normalised radial stress for the bearing test and countersunk joint with no bolt torque

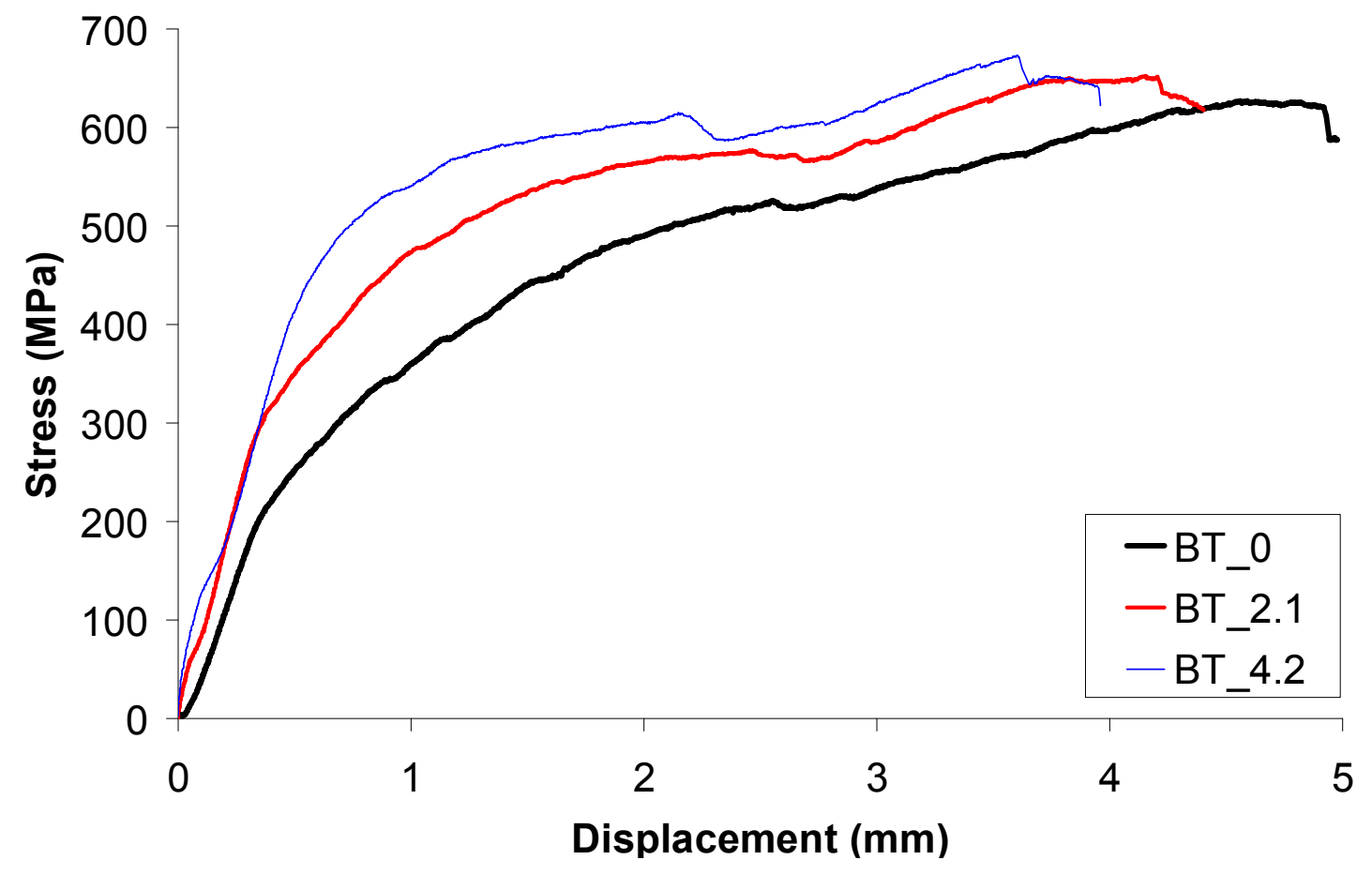

Figure 8: Countersunk joints, stress-displacement, bolt torque investigation 


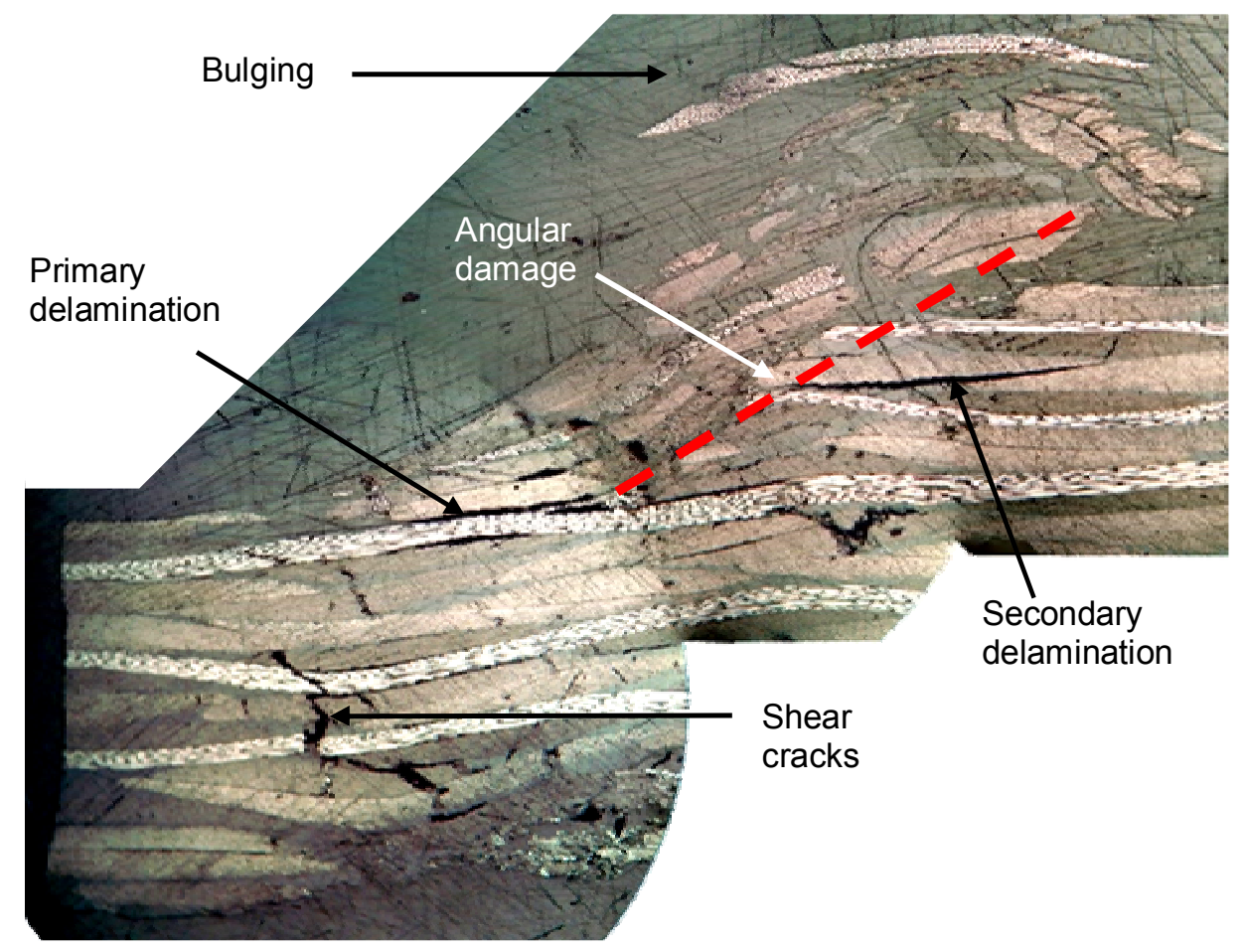

Figure 9: Countersunk joint $0^{\circ}$ section, BT_2.1 upper laminate

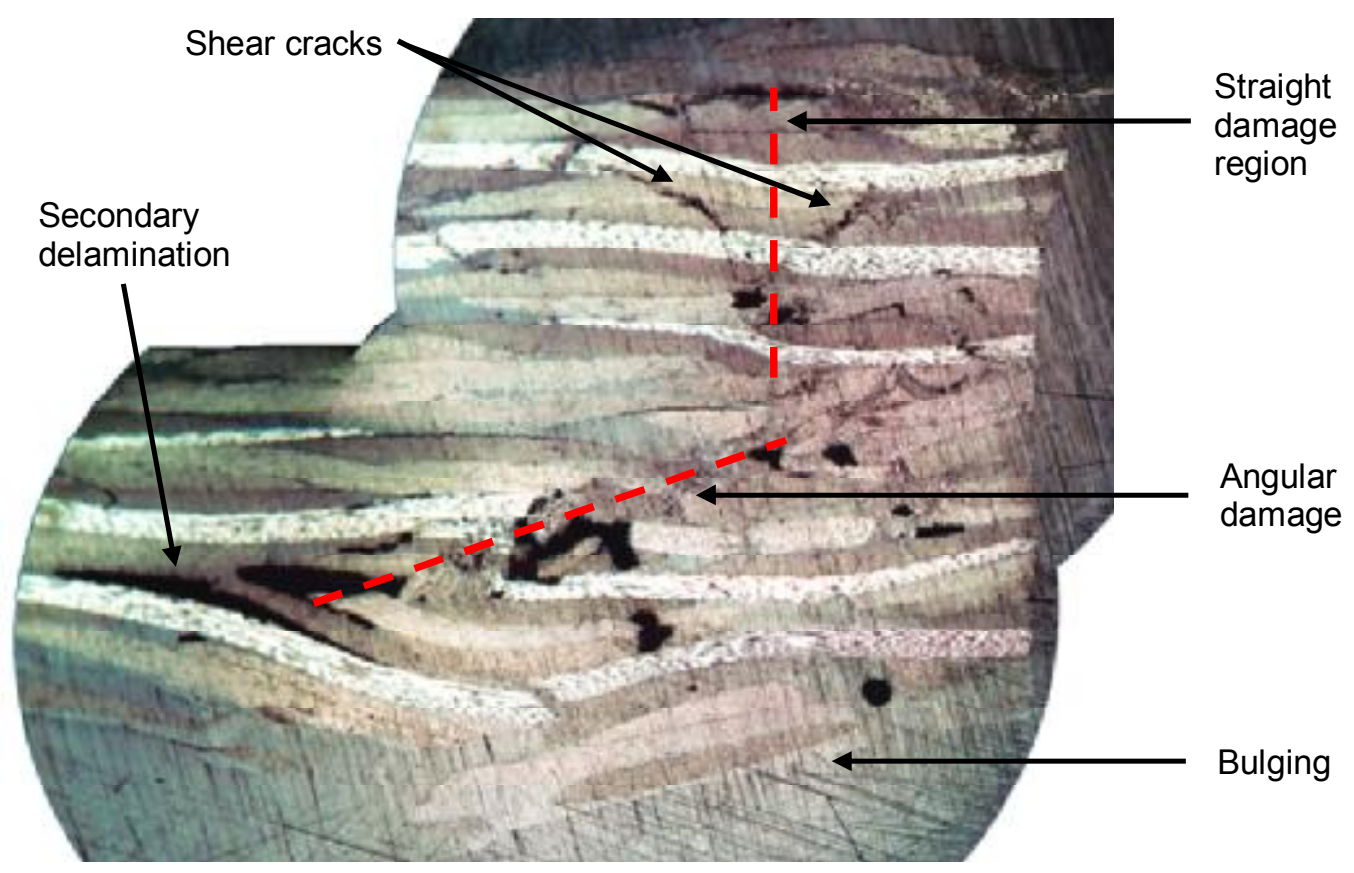

Figure 10: Countersunk joint $0^{\circ}$ section, BT_2.1 lower laminate 


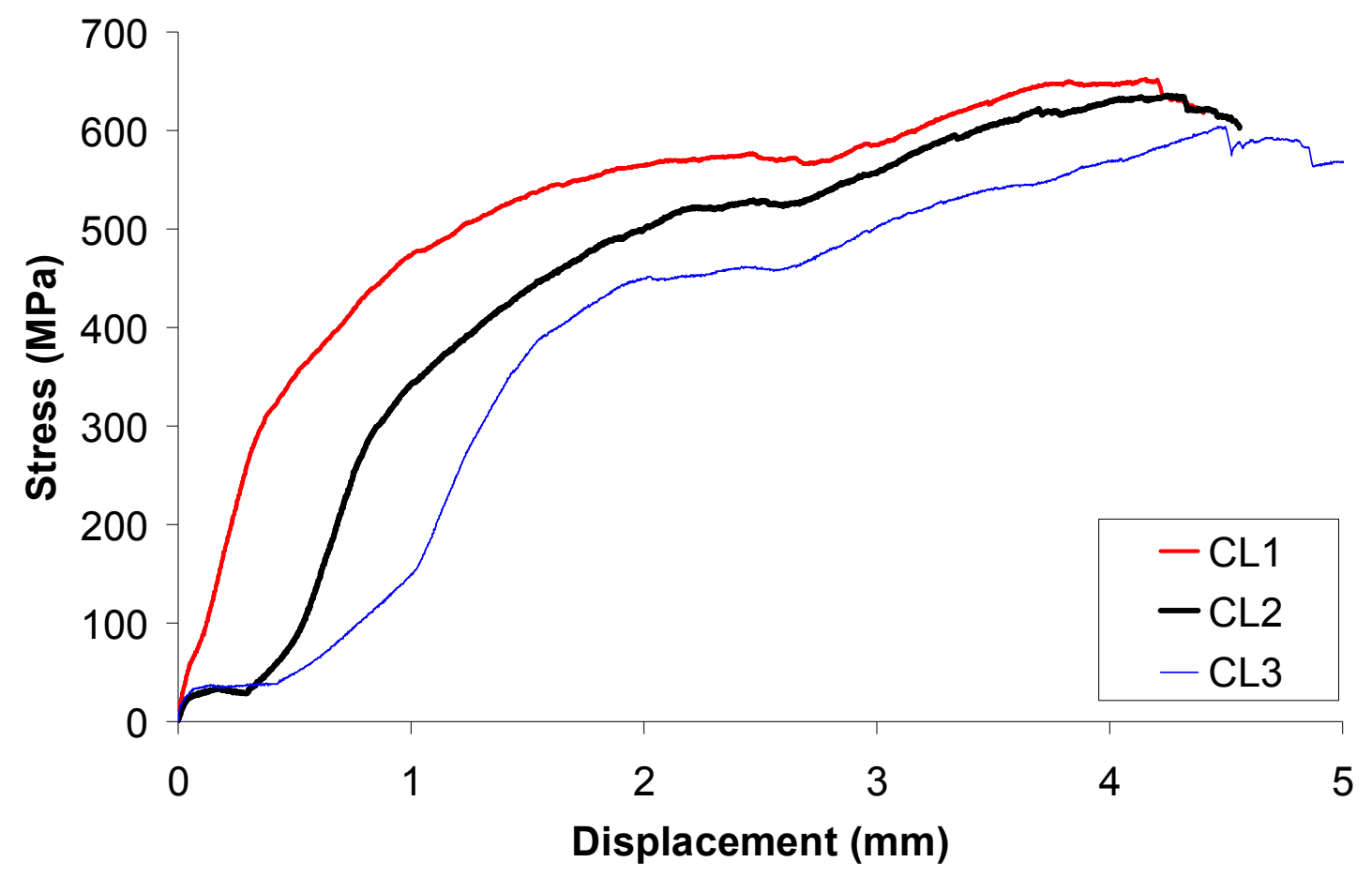

Figure 11: Countersunk joints, stress-displacement, bolt clearance investigation

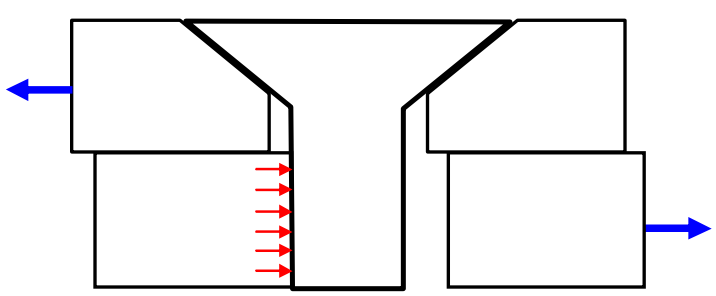

a) Initiation of bolt contact

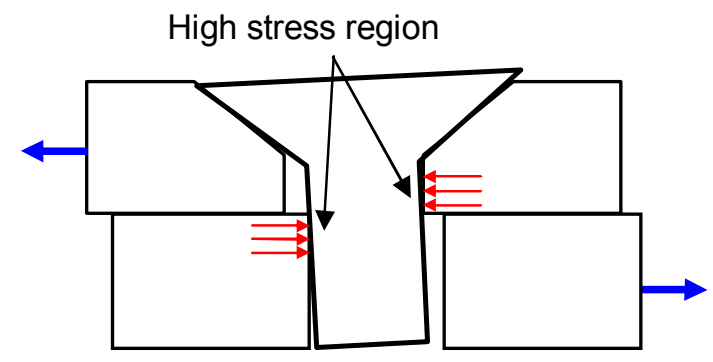

b) Bolt contact on both sides

Figure 12: Countersunk joint, load sequence with clearance 


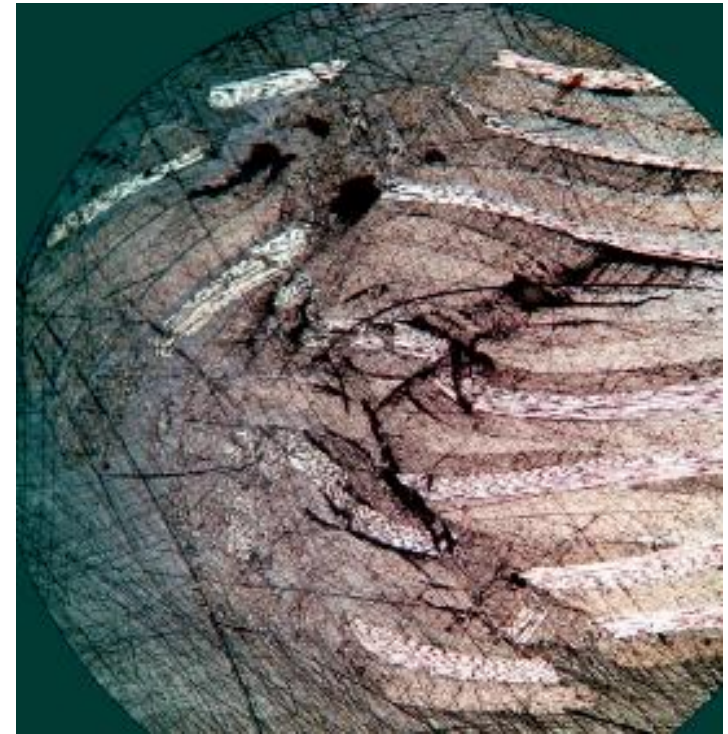

a) Upper laminate

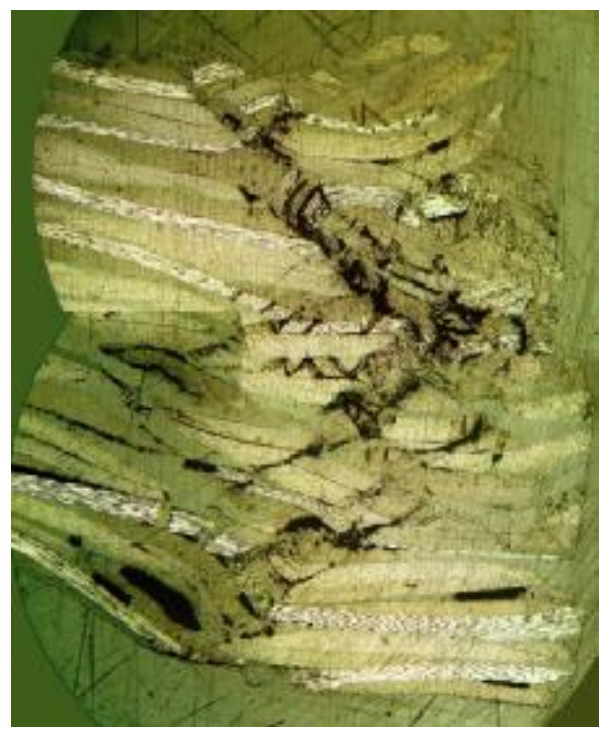

b) Lower laminate

Figure 13: Countersunk joint $0^{\circ}$ section, $C_{2} 240$

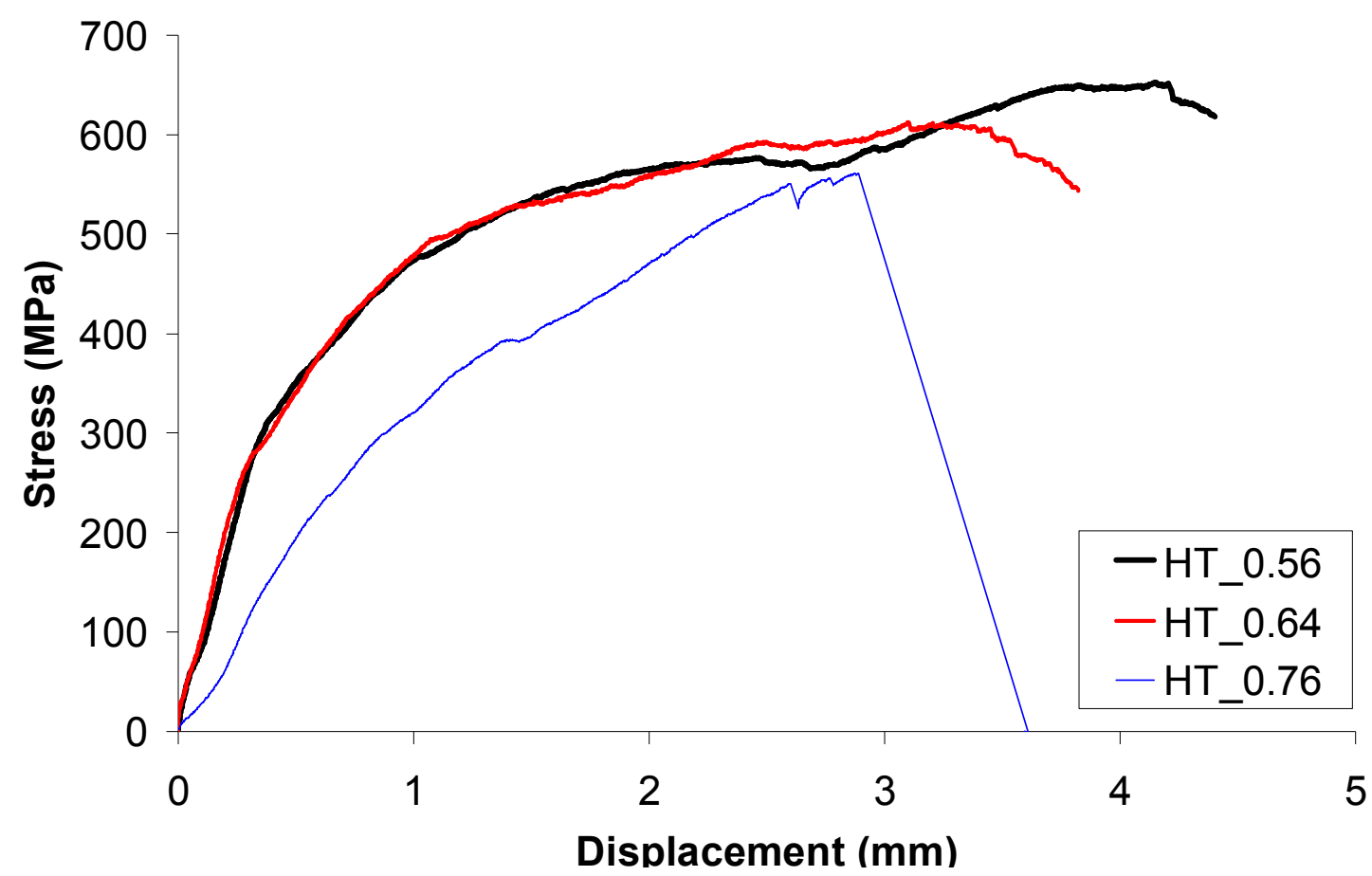

Figure 14: Countersunk joints, stress-displacement, height ratio investigation 


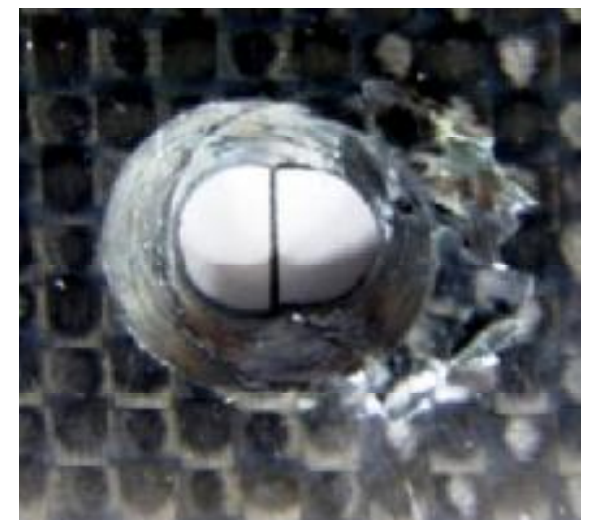

a) $h / t=0.56$

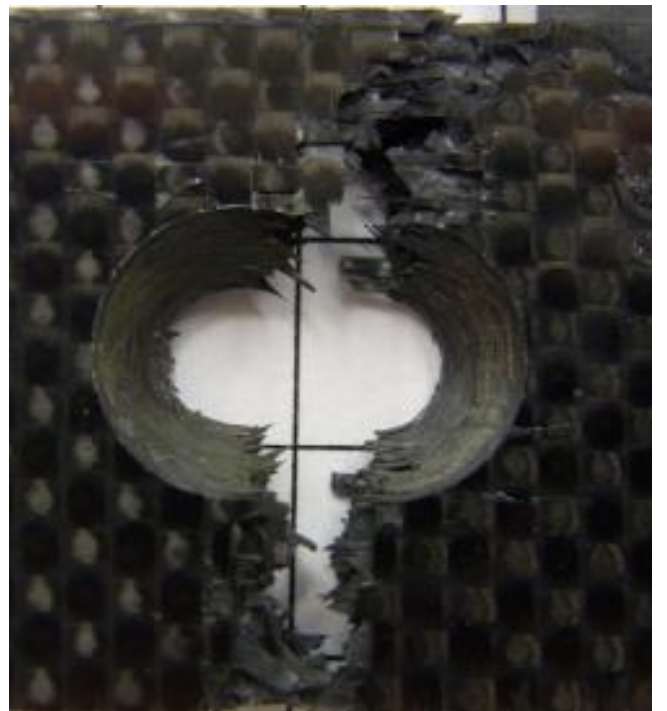

b) $h / t=0.76$

Figure 15: Countersunk joint upper laminate (countersink side) following ultimate failure 